\title{
ADUBAÇÃO FOSFATADA, COMPONENTES DE PRODUÇÃO, PRODUTIVIDADE E QUALIDADE FISIOLÓGICA EM SEMENTES DE FEIJÃO ${ }^{1}$
}

\author{
CLAUDEMIR ZUCARELI² ${ }^{2}$ EDISON ULISSES RAMOS JUNIOR ${ }^{2}$, ADRIANAPACHECO BARREIRO ${ }^{3}$, JOÃO NAKAGAWA ${ }^{4}$, CLAUDIO CAVARIANI $^{5}$
}

\begin{abstract}
RESUMO - O trabalho teve como objetivo avaliar o efeito de doses de fósforo aplicadas via solo, sobre os componentes de produção, produtividade e qualidade fisiológica de sementes de feijão, cv. IAC Carioca. Foram avaliadas seis doses de fósforo $\left(0,30,60,90,120\right.$ e $150 \mathrm{~kg} \cdot \mathrm{ha}^{-1}$ de $\left.\mathrm{P}_{2} \mathrm{O}_{5}\right)$ sob o delineamento experimental em blocos casualizados, com quatro repetições, em Latossolo Vermelho com baixo teor de fósforo $\left(6 \mathrm{mg} . \mathrm{dm}^{-3}\right)$, em condições de campo. No momento da colheita, avaliaramse estande final de plantas, altura da inserção da primeira vagem, comprimento das vagens, número de vagens/planta, número de sementes/vagem, número de lóculos/vagem, número lóculos vazios/ vagem, número de lóculos com sementes/vagem e massa de 100 sementes. A produtividade de sementes foi determinada com base na produção das duas linhas centrais de cada parcela, com teor de água corrigido para $13 \%$. A qualidade fisiológica das sementes foi avaliada pelos testes de germinação, primeira contagem de germinação, envelhecimento acelerado, condutividade elétrica, emergência de plântulas no campo e massa de matéria seca de plântulas. A adubação fosfatada com 150kg.ha-1 de $\mathrm{P}_{2} \mathrm{O}_{5}$ aumentou o número de vagens/planta e o número de sementes/planta. Os demais componentes de produção e a produtividade de sementes não foram alterados pela aplicação de fósforo. As doses de fósforo não alteraram a qualidade fisiológica das sementes de feijão, cv. IAC Carioca.
\end{abstract}

Termos para indexação: Phaseolus vulgaris, fósforo, fertilidade do solo, rendimento.

\section{PHOSPHORUS FERTILIZATION, PRODUCTION COMPONENTS, PRODUCTIVITYAND SEED PHYSIOLOGICAL QUALITY IN COMMONBEANS SEEDS}

\begin{abstract}
The objective of the research was to evaluate the effect of doses of phosphorus applied in the soil on production components, productivity and physiological quality of cv. IAC Carioca common beans seeds. Six doses of phosphorus (0, 30, 60, 90, 120 and 150kg.ha-1 of $\left.\mathrm{P}_{2} \mathrm{O}_{5}\right)$ were evaluated in a randomized block design, with four replications, in a "Latossolo Vermelho" with low phosphorus content $\left(6 \mathrm{mg} . \mathrm{dm}^{-3}\right)$, under field conditions. At harvesting, the final stand of plants was evaluated and the first green bean insertion height, green bean length, number of green beans per plant, number of seeds per plant, number of loculus per green bean, number of empty loculus per green bean, number of loculus with seeds per green bean and mass of 100 seeds were measured. Seed productivity was determined based on the two central production lines in each plot, which had the water content adjusted to $13 \%$. Seed physiological quality was evaluated by water content, germination test, first count of the germination test, accelerated aging, electric conductivity, seedling emergence in the field and seedling dry matter weight. Phosphorus fertilization with $150 \mathrm{~kg} \cdot \mathrm{ha}^{-1}$ of $\mathrm{P}_{2} \mathrm{O}_{5}$ increased the number of green beans per plant and the number of seeds per plant. The others production components and seed productivity were nott modified by the application of phosphorus. The doses of phosphorus did not modify the physiological quality of common beans seeds, cv. IAC Carioca.
\end{abstract}

Index terms: Phaseolus vulgaris, phosphorus, soil fertilization, yield.

${ }^{1}$ Submetido em 04/08/2004. Aceito para publicação em 06/06/2005;

${ }^{2} \mathrm{Eng}^{\mathrm{o}} \mathrm{Agr}^{\mathrm{0}}$ Msc. Doutorando, Dep. de Produção Vegetal - Agricultura, FCA/ UNESP, Botucatu - SP, CP 237, CEP 18603-970, claudemir@fca.unesp.br;

${ }^{3}$ Biologa Mestranda, Dep. de Botânica, IB/UNESP, Botucatu - SP;
${ }^{4}$ Eng $^{\text {o }}$ Agr $^{\circ}$ Dr. Volutario do Dep. de Produção Vegetal - Agricultura, FCA/ UNESP, Botucatu - SP, bolsista CNPq.

${ }^{5}$ Eng $^{\circ}$ Agr $^{\circ}$ Dr. Prof. Assistente, FCA, UNESP, Botucatu.CP 237, CEP 18603-970 


\section{INTRODUÇÃO}

O cultivo do feijoeiro (Phaseolus vulgaris L.) tem enfrentado problemas na maioria das regiões produtoras, devido à baixa produtividade que, provavelmente, tem suas causas assentadas na tecnologia rudimentar utilizada, nas variações climáticas e, principalmente, no esgotamento progressivo da fertilidade do solo. Assim, para obtenção de elevadas produtividades faz-se necessário o manejo adequado da fertilidade do solo (Pessoa et al., 1996).

O fósforo é um elemento essencial no metabolismo das plantas, desempenhando papel importante na transferência de energia da célula, na respiração e na fotossíntese. É também componente estrutural dos ácidos nucléicos de cromossomos, assim como de muitas coenzimas, fosfoproteínas e fosfolipídeos. Desse modo, limitações na disponibilidade de $\mathrm{P}$ no início do ciclo vegetativo podem resultar em restrições no desenvolvimento, das quais a planta não se recupera posteriormente, mesmo aumentando o suprimento de $\mathrm{P}$ a níveis adequados. O suprimento adequado de $\mathrm{P}$ é, diferentemente dos demais nutrientes, essencial desde os estádios iniciais de crescimento da planta (Grant et al., 2001).

O baixo teor de fósforo disponível no solo é a limitação nutricional mais generalizada na produção agrícola nos trópicos, sendo que, de acordo com Arf (1994), é o nutriente que mais influi na produtividade do feijoeiro na maioria dos solos brasileiros, no entanto, é baixa a eficiência da adubação fosfatada, pois grande parte do $\mathrm{P}$ adicionado torna se imóvel ou não disponível, em virtude de reações de adsorção em colóides minerais, precipitação ou conversão em formas orgânicas (Holford, 1997).

Segundo Fageria et al. (2003), a influência do P na cultura do feijoeiro reside no aumento da produção de matéria seca da parte aérea e aumento do número de vagens e massa de grãos, principais determinantes da produtividade. Contudo, dentre os componentes da produção, o número de vagens por unidade de área é o que mais contribui para o aumento da produtividade do feijão.

Ao avaliarem cultivares de feijão quanto à eficiência no uso de P, Oliveira et al. (1987) verificaram que o maior retorno de produção de grãos em relação ao nível de $\mathrm{P}$ aplicado fícou situado na faixa entre 30 e $120 \mathrm{~kg} \cdot \mathrm{ha}^{-1}$ de $\mathrm{P}_{2} \mathrm{O}_{5}$. Em condições de casa de vegetação, Fagéria (1989) constatou máxima produtividade de sementes com aplicação de 125 a $150 \mathrm{mg}$ de P. $\mathrm{kg}^{-1}$ de solo, dependendo da cultivar avaliada.

$\mathrm{O}$ aspecto nutricional das plantas afeta a produtividade, a obtenção de sementes de qualidade está associada a fatores como as condições ambientais e nível de nutrição da planta mãe (Arthur e Tonkin, 1991). A disponibilidade de nutriente influi na formação do embrião e dos órgãos de reserva e na composição química da semente, afetando, consequentemente, a qualidade da semente (Carvalho e Nakagawa, 2000). Segundo esses autores, o nível de vigor das sementes pode afetar o potencial de armazenamento do lote e persistir no campo, influenciando o estabelecimento da cultura, o desenvolvimento da planta, a uniformidade da lavoura e a sua produtividade.

Além da relação com a produção de sementes, inúmeros estudos tem sido realizados associando a adubação fosfatada à qualidade físiológica de sementes de várias espécies, como amendoim (Nakagawa et al., 1980; Marubayashi et al., 1997), soja (Mugnisjah e Nakamura, 1984), milho pipoca (Fornasieri Filho et al., 1988), girassol (Goya e Sader, 1990) e crotalária júncea (Dourado et al., 2001).

Em razão dos fatos relatados, estudos devem ser realizados com o intuito de se obterem subsídios para recomendação mais adequada da adubação fosfatada, visando à produção de sementes. Desse modo, o trabalho teve como objetivo avaliar o efeito de doses de fósforo aplicadas via solo sobre os componentes de produção, produtividade e qualidade fisiológica de sementes de feijão, cultivar IAC Carioca.

\section{MATERIAL E MÉTODOS}

O trabalho foi realizado em condições de campo na Fazenda Experimental Lageado, pertencente à Universidade Estadual Paulista, Faculdade de Ciências Agronômicas do Campus de Botucatu, que se encontra no município de Botucatu e está entre $22^{\circ} 30^{\prime}$ a $23^{\circ} 05^{\prime}$ de latitude $\mathrm{S}$ e $48^{\circ} 15^{\prime}$ ' a $48^{\circ} 52^{\prime}$ de longitude a oeste de Greenwich, com altitude de 750 metros. O clima da região, segundo a classificação de Köppen, é do tipo mesotérmico Cwb, ou seja, mesotérmico de inverno seco. A temperatura média de janeiro, mês mais quente do ano, não ultrapassa os $22^{\circ} \mathrm{C}$. A estação mais seca vai de maio a setembro e a precipitação pluvial média anual do Município é de $1.314 \mathrm{~mm}$, com temperatura média mensal de $19,4^{\circ} \mathrm{C}$.

O experimento foi conduzido no cultivo "das águas" em LATOSSOLO VERMELHO (Embrapa, 1999). A necessidade de calagem, a adubação básica de semeadura e a de cobertura, foram calculadas de acordo com Ambrosano et al. (1997) baseando-se nos resultados da análise química do solo $(0-20 \mathrm{~cm})$ que revelou $\mathrm{pH}=4,8 ; \mathrm{M} . \mathrm{O}=24 \mathrm{~g} \cdot \mathrm{dm}^{-3} ; \mathrm{P}=6 \mathrm{mg} \cdot \mathrm{dm}^{-3}$; $\mathrm{Al}^{3+}=2 \mathrm{mmol}_{\mathrm{c}} \cdot \mathrm{dm}^{-3} ; \mathrm{K}^{+}=3,5 \mathrm{mmol}_{\mathrm{c}} \cdot \mathrm{dm}^{-3} ; \mathrm{Ca}^{2+}=23 \mathrm{mmol}_{\mathrm{c}} \cdot \mathrm{dm}^{-3}$; 
$\mathrm{Mg}^{2+}=10 \mathrm{mmol}_{\mathrm{c}} \cdot \mathrm{dm}^{-3} ; \mathrm{SB}=36 ; \mathrm{CTC}=67 \mathrm{e} \mathrm{V} \%=54$.

O preparo do solo consistiu em uma aração e duas gradagens e os tratos culturais seguiram as recomendações para a cultura do feijoeiro. A semeadura foi realizada em 01/ 09/2002, utilizando a cultivar IAC Carioca, numa densidade de quinze sementes por metro para, após desbaste, obter população de 240.000 plantas por hectare. As sementes foram tratadas com Carboxim + Thiram na dose de $200 \mathrm{~mL} .100 \mathrm{~kg}$ ${ }^{1}$ de semente. Foram avaliadas seis doses de fósforo $(0,30$, 60, 90, 120 e $150 \mathrm{~kg} \cdot \mathrm{ha}^{-1}$ de $\mathrm{P}_{2} \mathrm{O}_{5}$ ) utilizando como fonte o superfosfato triplo, sob o delineamento experimental em blocos casualizados, com quatro repetições. Foram aplicados $10 \mathrm{~kg} \cdot \mathrm{ha}^{-1}$ de $\mathrm{K}_{2} \mathrm{O}$ e de $\mathrm{N}$ na semeadura e $60 \mathrm{~kg} \cdot \mathrm{ha}^{-1}$ de $\mathrm{N}$ em cobertura, parcelados aos 15 e 30 dias após a emergência das plântulas.

A parcela experimental foi constituída por seis linhas de 10 metros de comprimento com espaçamento entre linhas de 0,5 metro. A área útil de cada parcela experimental foi constituída pelas duas linhas centrais, desprezando-se 0,5 metro de cada extremidade, totalizando $18 \mathrm{~m}^{2}$. Na colheita, realizada em 16/12/2002, avaliou-se o estande final de plantas e coletou-se 10 plantas das linhas centrais de cada parcela para determinação dos componentes da produção (altura da inserção da primeira vagem, comprimento das vagens, número de vagens/planta, número de sementes/vagem, número de lóculos/vagem, número lóculos vazios/vagem e número de lóculos com sementes/vagem e a massa de 100 sementes).

A produtividade de sementes foi determinada com base na produção da parcela útil, com teor de água corrigido para $13 \%$. A qualidade fisiológica das sementes foi avaliada mediante as determinações discriminadas a seguir:

Teor de água: determinado utilizando-se 25 sementes para cada repetição dos tratamentos, em estufa regulada a $105 \pm 3^{\circ} \mathrm{C}$, durante 24 horas, conforme as Regras para Análise de Sementes (Brasil, 1992).

Germinação: conduzido com 50 sementes para cada repetição dos tratamentos, em papel toalha umedecido com água na proporção de 2,5 vezes a massa do substrato. Os rolos de papel, acondicionados em sacos plásticos, foram mantidos em germinador a $25^{\circ} \mathrm{C}$. As contagens foram realizadas aos cinco e nove dias após a instalação do teste, seguindo os critérios estabelecidos em Brasil (1992).

Primeira contagem de germinação: realizada concomitantemente ao teste de germinação, determinando-se a porcentagem das plântulas normais obtidas aos cinco dias após a instalação do teste.

Condutividade elétrica: 25 sementes, por repetição dos tratamentos, com massa conhecida foram colocadas para embeber em recipientes plásticos contendo $75 \mathrm{~mL}$ de água destilada, por um período de 24 horas e mantidas a $25^{\circ} \mathrm{C}$. Em seguida, as amostras foram agitadas para homogeneização dos exsudatos liberados na água, efetuando-se a leitura da condutividade elétrica da solução de embebição em condutivímetro com eletrodo de constante 1,0, expressandose os resultados em mS.cm-1. $\mathrm{g}^{-1}$ de sementes (Vieira, 1994).

Envelhecimento acelerado: foi adotada a metodologia descrita por Marcos Filho (1999), utilizando 75 sementes por repetição dos tratamentos. As sementes foram distribuídas em camada única, sobre bandeja de tela metálica fixada no interior de caixa plástica contendo $40 \mathrm{~mL}$ de água. As caixas, tampadas e acondicionadas em sacos plásticos foram mantidas a $42^{\circ} \mathrm{C}$ por 72 horas. Após este período, 25 sementes por repetição foram submetidas à determinação do teor de água e 50 sementes por repetição foram submetidas ao teste de germinação, com avaliação aos cinco dias após a instalação do teste, computando-se a porcentagem de plântulas normais.

Emergência de plântulas no campo: realizado com 50 sementes para cada repetição dos tratamentos. As sementes foram semeadas em sulco com $2,5 \mathrm{~m}$ de comprimento e $2,0 \mathrm{~cm}$ de profundidade, simulando a semeadura no campo, sendo irrigadas sempre que necessário. A contagem das plântulas emergidas foi efetuada aos 14 dias após a semeadura com expressão dos resultados em porcentagem (Nakagawa, 1994).

Massa de matéria seca de plântula: obtida pela determinação da massa das plântulas provenientes da emergência de plântulas no campo, colhidas aos 14 dias de sua emergência e secadas em estufa com circulação de ar a $60^{\circ} \mathrm{C}$ até peso constante, sendo os valores expressos em g.plântula ${ }^{-1}$.

Os resultados dos parâmetros avaliados foram submetidos à análise de variância e as médias comparadas pelo teste de Tukey a $5 \%$ de probabilidade. Os dados foram, também, submetidos à análise de regressão.

\section{RESULTADOS E DISCUSSÃO}

Na Tabela 1 são apresentados os resultados referentes à população final de plantas, altura da inserção da primeira vagem, número de sementes por vagem, comprimento de vagens, número total de lóculos por vagem, número de lóculos cheios por vagem, número de lóculos vazios por vagem, massa de 100 sementes e produtividade de sementes de feijão em função de doses de fósforo.

A população de plantas por ocasião da colheita não variou 
TABELA1. População de plantas (POP), altura da inserção da primeira vagem (AIV), número de sementes por vagem (S/V), comprimento de vagens (CV), número total de lóculos (TL), número de lóculos cheios, número de lóculos vazios, massa de 100 sementes (M100) e produtividade (Prod) de sementes de feijão em função da adubação fosfatada. Botucatu, 2003

\begin{tabular}{cccccccccc}
\hline $\begin{array}{c}\text { Doses } \\
\left(\mathrm{kg} \mathrm{P}_{2} \mathrm{O}_{5} \cdot \mathrm{ha}^{-1}\right)\end{array}$ & $\begin{array}{c}\text { Pop } \\
\left(\mathrm{pl}^{-1} \mathrm{ha}^{-1}\right)\end{array}$ & $\begin{array}{c}\text { AIV } \\
(\mathrm{cm})\end{array}$ & S/V & $\begin{array}{c}\mathrm{CV} \\
(\mathrm{cm})\end{array}$ & TL & $\begin{array}{c}\text { Lóculos } \\
\text { cheios }\end{array}$ & $\begin{array}{c}\text { Lóculos } \\
\text { vazios }\end{array}$ & $\begin{array}{c}\text { M100 } \\
(\mathrm{g})\end{array}$ & $\begin{array}{c}\text { Prod } \\
\left(\mathrm{kg}^{-h^{-1}}\right)\end{array}$ \\
\hline 0 & 206250 & 18,6 & 4,4 & 8,6 & 5,8 & 4,8 & 1,0 & 28,12 & 1973 \\
30 & 215500 & 20,0 & 4,0 & 8,2 & 6,3 & 4,8 & 0,8 & 26,37 & 2067 \\
60 & 223500 & 21,0 & 4,0 & 8,3 & 5,5 & 5,3 & 0,5 & 26,50 & 2107 \\
90 & 224000 & 22,1 & 4,3 & 8,5 & 6,0 & 5,3 & 1,0 & 26,75 & 2126 \\
120 & 227500 & 22,3 & 4,1 & 8,1 & 5,5 & 5,0 & 1,0 & 28,00 & 2186 \\
150 & 241250 & 22,0 & 4,0 & 8,3 & 5,5 & 5,0 & 0,8 & 26,50 & 2508 \\
\hline $\mathrm{CV}(\%)$ & 7,8 & 17,91 & 9,38 & 4,9 & 10,45 & 10,5 & 82,5 & 5,08 & 20,9 \\
DMS & 39209 & 4,5 & 0,9 & 0,9 & 1,4 & 1,2 & 1,5 & 2,1 & 1013 \\
F & $1,82^{\text {ns }}$ & $0,62^{\text {ns }}$ & $0,57^{\text {ns }}$ & $0,56^{\text {ns }}$ & $1,10^{\text {ns }}$ & $0,72^{\text {ns }}$ & $0,35^{\text {ns }}$ & $2,72^{\text {ns }}$ & $0,67^{\text {ns }}$ \\
\hline
\end{tabular}

ns: não significativo

entre os tratamentos, com média de 223.000 plantas ha-1, contudo o aumento nas doses de fósforo mostrou tendência em favorecer o estabelecimento da cultura, reduzindo perdas de plantas durante o ciclo. As doses de fósforo avaliadas, também, não exerceram efeito sobre a altura de inserção da primeira vagem, com média entre tratamentos de $20,9 \mathrm{~cm}$, sendo observado menor valor numérico em plantas provenientes da menor dose e o maior na dose de $120 \mathrm{~kg} \cdot \mathrm{ha}^{-1}$ de $\mathrm{P}_{2} \mathrm{O}_{5}$

O número de vagens por planta (Figura 1) foi afetado pelas doses de fósforo, segundo relação quadrática. $\mathrm{O}$ menor número de vagens foi observado na dose de $30 \mathrm{~kg} \cdot \mathrm{ha}^{-1}$ de $\mathrm{P}_{2} \mathrm{O}_{5}$ e o maior número na dose de $150 \mathrm{~kg} \cdot \mathrm{ha}^{-1}$ de $\mathrm{P}_{2} \mathrm{O}_{5}$. De acordo com Haag et al. (1978), o número de vagens/planta de feijoeiro foi o componente que exerceu maior influência na produção de grãos, tanto em baixa quanto em alta dose de P. Em cultivares de feijão, Vidal e Junqueira Netto (1982) constataram aumento do número de vagens por parcela em função do aumento das doses de fósforo.

O número de sementes por planta (Figura 2) seguiu comportamento semelhante ao observado no número de vagens por planta, com relação quadrática; as doses de 30 e $150 \mathrm{~kg}$.ha- ${ }^{-1}$ de $\mathrm{P}_{2} \mathrm{O}_{5}$ resultaram no menor $(36,70)$ e maior $(50,23)$ número de sementes/planta, respectivamente. Segundo Oliveira et al. (1996), plantas de feijoeiro deficientes em $\mathrm{P}$ perdem o vigor, reduzem o número de vagem e produzem menos grãos, reduzindo a produção.

O comprimento das vagens não foi afetado pela adubação fosfatada, resultando em comprimento médio de $8,3 \mathrm{~cm}$. Do mesmo modo, o número de sementes por vagem também não foi alterado em função das doses de P. Assim, o aumento

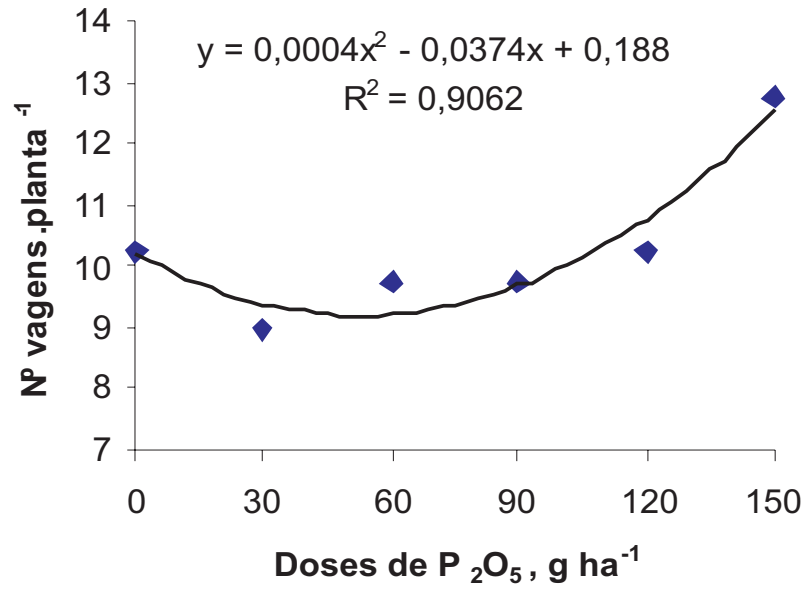

FIGURA 1. Número de vagens por planta em função de doses de fósforo.

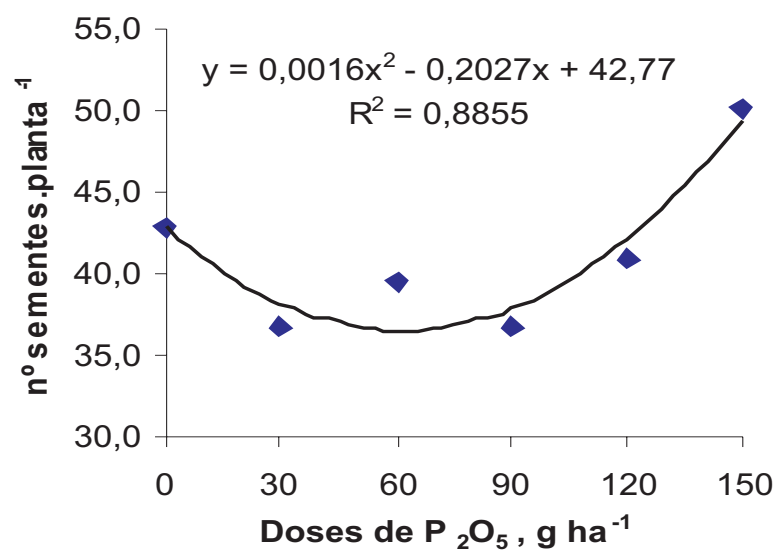

FIGURA 2. Número de sementes por planta em função de doses de fósforo no solo.

constatado no número de sementes/planta foi resultante do aumento do número de vagens/planta, já que o número de sementes/vagem não sofreu alteração. Em condições de baixa 
disponibilidade de $\mathrm{P}$, linhagens de feijoeiro apresentaram maior número de sementes/vagem (Youngdahl, 1990). Entretanto, ao avaliar a adubação residual de $\mathrm{P}$ sobre os componentes de produção do feijoeiro, Salum et al. (2003) obtiveram maior número de sementes/vagem na dose de $120 \mathrm{~kg} \cdot \mathrm{ha}^{-1}$ de $\mathrm{P} 2 \mathrm{O} 5$ em relação à de $90 \mathrm{~kg} \cdot \mathrm{ha}^{-1}$.

Os tratamentos avaliados também não afetaram o número total de lóculos, de lóculos cheios e de lóculos vazios, com médias de 5,8, 5,0 e 0,8, respectivamente. A massa de 100 sementes também não foi alterada pela adubação fosfatada. As plantas respondem à deficiência de $\mathrm{P}$ com adaptações que possibilitam a produção de sementes viáveis; o estresse de $\mathrm{P}$ diminui mais o número total de sementes produzidas que o tamanho da semente (Grant et al., 2001), dando suporte aos resultados obtidos, ou seja, menor número de vagens e de sementes por planta e maior peso de sementes nas menores doses de P avaliadas. Contudo, Singh et al. (1989) relataram redução na massa de 100 sementes em feijão cultivado em solo com baixo teor de $\mathrm{P}$.

Apesar do experimento ter sido implantado em solo com teor muito baixo de $\mathrm{P}$, a produtividade de sementes não variou com os tratamentos avaliados, com média de 2161,2kg.ha- ${ }^{-1}$; entretanto, observou-se tendência de aumentos na produtividade com a elevação das doses fósforo aplicadas. Essa tendência pode ser relacionada ao número de vagens e sementes por planta, que aumentaram com a aplicação de P. Ao avaliarem cultivares de feijão quanto à eficiência no uso de fósforo (Oliveira et al., 1987) verificaram que o maior retorno de produção de sementes em relação ao nível de $\mathrm{P}$ aplicado ficou situado na faixa entre 30 e $120 \mathrm{~kg} \cdot \mathrm{ha}^{-1}$ de $\mathrm{P}_{2} \mathrm{O}_{5}$. Contudo, Silveira e Moreira (1990) ao estudarem a resposta do feijoeiro a doses de fósforo e lâminas de água, sob condições de campo, constataram aumentos no rendimento de sementes do feijoeiro com a aplicação de doses crescentes de fósforo, com respostas variáveis de acordo com a lâmina de água aplicada; contudo, melhores resultados foram obtidos na dose de $400 \mathrm{~kg} \cdot h \mathrm{ha}^{-1}$ de $\mathrm{P}_{2} \mathrm{O}_{5}$.

$\mathrm{O}$ teor de água das sementes, tanto antes quanto após o envelhecimento acelerado não apresentou diferença entre os tratamentos (Tabela 2), indicando que não deve ter afetado os resultados das avaliações de qualidade. Em relação à qualidade fisiológica das sementes (Tabela 2), os tratamentos com 60 e 90kg.ha-1 de $\mathrm{P}_{2} \mathrm{O}_{5}$ diferiram quanto à porcentagem de plântulas normais, tanto na germinação como na primeira contagem de germinação, com menores valores para a dose de $90 \mathrm{~kg} \cdot \mathrm{ha}^{-1}$ de $\mathrm{P}_{2} \mathrm{O}_{5}$. Os tratamentos com fósforo, todavia, não diferiram da testemunha (sem fósforo), nestas avaliações.

A porcentagem de plântulas normais após o envelhecimento acelerado foi superior nas doses de $30 \mathrm{e}$ $60 \mathrm{~kg} \cdot \mathrm{ha}^{-1}$ de $\mathrm{P}_{2} \mathrm{O}_{5}$ em relação à de $90 \mathrm{~kg} \cdot$ ha $^{-1}$ de $\mathrm{P}_{2} \mathrm{O}_{5}$ e não diferiram dos demais tratamentos. Menor valor de condutividade elétrica foi obtido na ausência de aplicação de $\mathrm{P}$ no solo, diferindo-se apenas da dose de $90 \mathrm{~kg} \cdot \mathrm{ha}^{-1}$ de $\mathrm{P}_{2} \mathrm{O}_{5}$. Os tratamentos de $\mathrm{P}$ avaliados não proporcionaram diferenças quanto à porcentagem de emergência de plântulas no campo e à massa de matéria seca de plântulas.

Interpretando os resultados do conjunto de testes, podese inferir que as doses avaliadas não diferiram quanto à qualidade fisiológica das sementes, incluindo o tratamento sem fósforo, fato que pode estar associado ao desenvolvimento de estratégias pela planta para maximizar a probabilidade de produzir sementes viáveis, como a manutenção da qualidade fisiológica em detrimento à quantidade de sementes produzidas, quando sob condições de deficiência de $\mathrm{P}$, como

TABELA 2. Teor de água (TA), germinação (G), primeira contagem de germinação (PC), Envelhecimento acelerado (EA) e teor de água após envelhecimento acelerado (TAEA), condutividade elétrica (CE), emergêMédias seguidas de mesma letra na vertical não diferem entre si pelo teste de Tukey a $5 \%$ de probabilidade

\begin{tabular}{ccccccccc}
\hline $\begin{array}{c}\text { Doses de } \mathrm{P}_{2} \mathrm{O}_{5} \\
\left(\mathrm{~kg} \cdot \mathrm{ha}^{-1}\right)\end{array}$ & TA $(\%)$ & $\begin{array}{c}\mathrm{G} \\
(\%)\end{array}$ & $\begin{array}{c}\mathrm{PC} \\
(\%)\end{array}$ & $\begin{array}{c}\text { EA } \\
(\%)\end{array}$ & $\begin{array}{c}\text { TAEA } \\
(\%)\end{array}$ & $\begin{array}{c}\mathrm{CE} \\
\left(\mu \mathrm{mS}_{\mathrm{c}} \mathrm{cm}^{-1} \cdot \mathrm{g}^{-1}\right)\end{array}$ & $\begin{array}{c}\text { EC } \\
(\%)\end{array}$ & $\begin{array}{c}\text { MSPL } \\
(\mathrm{g})\end{array}$ \\
\hline 0 & 12,1 & $89,5 \mathrm{ab}$ & $84,0 \mathrm{abc}$ & $81,8 \mathrm{ab}$ & 32,4 & $50,2 \mathrm{~b}$ & 90 & 0,265 \\
30 & 12,2 & $83,0 \mathrm{ab}$ & $78,3 \mathrm{bc}$ & $83,3 \mathrm{a}$ & 32,9 & $57,2 \mathrm{ab}$ & 84 & 0,257 \\
60 & 12,3 & $92,5 \mathrm{~b}$ & $92,0 \mathrm{a}$ & $84,3 \mathrm{a}$ & 32,8 & $55,1 \mathrm{ab}$ & 90 & 0,247 \\
90 & 12,6 & $80,3 \mathrm{~b}$ & $72,5 \mathrm{c}$ & $70,5 \mathrm{~b}$ & 33,3 & $63,5 \mathrm{a}$ & 84 & 0,228 \\
120 & 13,0 & $93,0 \mathrm{a}$ & $89,5 \mathrm{ab}$ & $81,0 \mathrm{ab}$ & 32,4 & $56,0 \mathrm{ab}$ & 93 & 0,246 \\
150 & 12,8 & $85,0 \mathrm{ab}$ & $81,3 \mathrm{abc}$ & $80,3 \mathrm{ab}$ & 31,9 & $55,3 \mathrm{ab}$ & 83 & 0,252 \\
\hline $\mathrm{CV}(\%)$ & 7,7 & 7,9 & 9,6 & 9,9 & 4,7 & 15,6 & 8,50 & 13,21 \\
$\mathrm{DMS}$ & 2,2 & 10,4 & 12,03 & 12,06 & 3,5 & 13,20 & 16,70 & 0,075 \\
$\mathrm{~F}$ & $0,99^{\text {ns }}$ & $4,60^{* *}$ & $6,54^{* *}$ & $3,07^{* *}$ & $0,40^{\text {ns }}$ & $1,91^{*}$ & $1,16^{\text {ns }}$ & $0,57^{\text {ns }}$ \\
\hline
\end{tabular}

***, significativo a 1 e $5 \%$, respectivamente.

ncia no campo (EC) e massa de matéria seca de plântulas de sementes de feijão em função de doses de fósforo. Botucatu, 2003 
relatado por Grant et. al (2001).Da mesma forma, Salum et al. (2003) não constataram efeito residual da adubação com fósforo, nas mesmas doses e cultivar aqui avaliado, sobre a qualidade fisiológica de sementes. Entretanto, Zucareli et al. (2003) ao avaliarem a qualidade fisiológica de sementes de feijão, cv. Carioca Precoce, em função da adubação fosfatada e da classificação das sementes por tamanho, constataram que as doses de 0,90 e $150 \mathrm{~kg} \cdot h a^{-1}$ de $\mathrm{P}_{2} \mathrm{O}_{5}$ resultaram sementes de melhor qualidade fisiológica nas de maior tamanho, porém, sem efeito nas menores.

A falta de resposta à adubação fosfatada, observada neste trabalho para a maioria dos parâmetros avaliados, pode estar associada à cultivar utilizada, pois Fageria (1998), ao avaliar genótipos de feijão quanto à eficiência do uso de $\mathrm{P}$, considerou a cultivar IAC Carioca eficiente, porém não responsiva à adubação fosfatada quanto à produção de matéria seca/ quantidade de fósforo absorvida. Pode se inferir, portanto, que a cultivar também não é responsiva a adubação fosfatada quanto à qualidade fisiológica da semente.

\section{CONCLUSÕES}

A adubação fosfatada com $150 \mathrm{~kg}$.ha- $\mathrm{de}^{-1} \mathrm{P}_{2} \mathrm{O}_{5}$ aumentou o número de vagens/planta e o número de sementes/planta; os demais componentes de produção e a produtividade de sementes não foram alterados pela aplicação de fósforo.

Os tratamentos de fósforo não afetaram a qualidade fisiológica das sementes de feijão da cultivar, IAC Carioca.

\section{REFERÊNCIAS}

AMBROSANO, E.J.; WUTKE, E.D.; BULISANI, E.A.; CANTARELA, H. Leguminosas e oleaginosas In: Van RAIJ B.; H. CANTARELLA, J.A. QUAGGIO; FURLANI, A.M.C., Recomendações de adubação e calagem para o Estado de São Paulo. 2 ed. rev. atual. Campinas: Instituto Agronômico/Fundação IAC, 1997. 285p.( Boletim Técnico, 100).

ARF, O. Importância da adubação na qualidade do feijão e caupi. In: SÁ, M.E.; BUZZETI, S. Importância da adubação na qualidade dos produtos agrícolas. São Paulo, 1994. p.233-248.

ARTHUR, T.J.; TONKIN, J.H.B. Testando o vigor da semente. Informativo ABRATES, Londrina, v.1, n.3, p. 38-42, 1991.

BRASIL Ministério da Agricultura e Reforma Agrária. Regras para análise de sementes. Brasília: SNDA/ DNDV/CLAV, 1992. $364 p$.

CARVAlho, N.M.; NAKAGAWA, J. Sementes: ciência, tecnologia e produção. Jaboticabal: FUNEP, 2000. 429p.

DOURADO, M.C.; SILVA, T.R.B.; BOLONHEZI, A.C. Matéria seca e produção de grãos de Crotalária júncea $\mathrm{L}$. submetida à poda e adubação fosfatada. Scientia Agricola, Piracicaba, v.58, n.2, 2001.
EMPRESA BRASILEIRA DE PESQUISA AGROPECUÁRIA. Centro Nacional de Pesquisa de Solos. Sistema brasileiro de classificação de solos. Brasília: Embrapa Produção de Informação; Rio de Janeiro:Embrapa Solos, 1999. XXVI, 412p.

FAGERIA, N.K. Effects of phosphorus on growth, yeld and nutrient accumulation in the common bean. Tropical Agriculture, London, v.66, n.3, 1989.

FAGERIA, N.K. Eficiência de uso de fósforo pelos genótipos de feijão. Revista Brasileira de Engenharia Agrícola e Ambiental, Campina Grande, v.2, n.2, p.128-131. 1998.

FAGERIA, N.K.; BARBOSA FILHO, M.P.; STONE, L.F. Resposta do feijoeiro a adubação fosfatada. In: POTAFÓS. Simpósio destaca a essencialidade do fósforo na agricultura brasileira. Informações Agronômicas, Piracicaba, n.102, p.1-9, 2003.

FORNASIERI FILHO, D.; BRANDÃO, S.S.; SADER, R.; VITTI, G.C. Efeito do fósforo e do zinco sobre a composição mineral e qualidade fisiológica das sementes de milho pipoca. Revista Brasileira de Sementes, Brasília, v.10, n.1, p.43-53, 1988.

GOYA, P.G.R.; SADER, R. Efeito da adubação fosfatada na qualidade de sementes de girassol da cv. IAC-Anhandy. Revista Brasileira de Sementes, Brasília, v.12, n.3, p.17-27, 1990.

GRANT, C.A.; PLATEN, D.N.; TOMAZIEWICZ，D.J.; SHEPPARD, S.C. A importância do fósforo no desenvolvimento inicial da planta. Informações Agronômicas, Piracicaba, n.95, 2001.

HAAG, W.L.; ADANS, M.W.; WIERSMA, J.V. Differential responses of dray bean genotypes to $\mathrm{N}$ and $\mathrm{P}$ fertilization of a Central Americam soil. Agronomy Journal, Madison, v.70, p.565568,1978

HOLFORD, I.C.R. Soil phosphorus: its measurement, and its uptake by plants. Aust. Journal Soil Research, v.35, p.227-239, 1997.

MARCOS FILHO, J. Teste de envelhecimento acelerado. In: KRZYZANOWSKI, F.C.; VIEIRA, R.D.; FRANÇA NETO, J.B. (Ed.)Vigor de sementes: conceitos e testes. Londrina: ABRATES, 1999. p.3.1-3.21.

MARUBAYASHI, O.M.; ROSOLEN, C.A.; NAKAGAWA, J.; ZANOTTO, M.D. Adubação fosfatada, produção e qualidade de sementes de populações de amendoim. Pesquisa Agropecuária Brasileira, Brasília, v.32, n.9, p.885-92, 1997.

MUGNISJAH, W.Q.; NAKAMURA, S. Vigour of soybean seed produced from different harvest date and phosphorus fertiliser application. Seed Science and Technology, Zürich, v.12, p.483-91, 1984.

NAKAGAWA, J. Testes de vigor baseados na avaliação de plântulas. In: VIEIRA, R. D.; CARVALHO, N. M. (Ed.). Testes de vigor em sementes. Jaboticabal: FUNEP, 1994. p.48-85.

NAKAGAWA, J.; ROSOLEN, C.A.; MACHADO, J.R. Efeitos da adubação fosfatada no vigor das sementes de amendoim. Revista Brasileira de Sementes, Brasília, v.2, n.1, p.67-74, 1980.

OLIVEIRA, I.P.; THUNG, M.; KLUTHCOUSKI, J.; AIDAR, H.; CARVALHO, J.R. Avaliação de cultivares de feijão quanto a eficiência no uso de fósforo. Pesquisa Agropecuária Brasileira, Brasília, v.22, n.1, p.39-45, 1987.

OLIVEIRA, I.P.; ARAÚJO, R.S.; DUTRA, L.G. Nutrição mineral e 
fixação biológica do nitrogênio. In: ARAUJO, R.S.; RAVA, C.A.; STONE, L.F.; ZIMMERMANN, M.J.O. Cultura do feijoeiro comum no Brasil. Potafós, 1996. 786p.

PESSOA, A.C.S.; KELLING, C.R.S.; POZZEBON, E.J.; KONIG, O. Concentração e acumulação de nitrogênio, fósforo e potássio pelo feijoeiro cultivado sob diferentes níveis de irrigação. Ciência Rural, Santa Maria, v.16, n.1, p.69-74, 1996.

SALUM, J.D.; RAMOS JÚNIOR, E.U.; ZUCARELI, C. FERNANDES, D.M.; NAKAGAWA, J. Adubação residual com fósforo nos componentes de produção, produtividade e qualidade fisiológica de sementes de feijão. Informativo ABRATES, Londrina, v.13, n.3, p.265, 2003.

SILVEIRA, P.M.; MOREIRA, J.A.A. Resposta do feijoeiro a doses de fósforo e lâminas de água de irrigação. Revista Brasileira de Ciência do Solo, Brasília, v.14, p.63-67, 1990.

SINGH, S.P.; URREA, C.A.; GUTIERRES, J.A.; GARCIA, J. Seletion for yield at two fertilizer levels in small-seeded common bean. Canadian Journal Plant Science, Ottawa, v.69, p.1011-1017, 1989.

VIDAL, L. S.; JUNQUEIRA NETTO, A. Efeitos da densidade de plantas e de doses de fósforo sobre algumas características de duas cultivares de feijão (Phaseolus vulgaris L.). Ciência Prática, Lavras, v.6, n.2, p.195-207, 1982.

VIEIRA, R.D. Teste de condutividade elétrica. In: VIEIRA, R.D., CARVALHO, N.M. (Ed)Testes de vigor em sementes. Jaboticabal: FUNEP/UNESP, 1994. p.103-132.

YOUNGDAHL, L.J. Differences in phosphorus efficiency in bean genotypes. Journal of Plant Nutrition, New York, v.13, p.13811392, 1990.

ZUCARELI, C.; RAMOS JÚNIOR, E.U.; ANDRÉO, Y.; NAKAGAWA, J. Adubação fosfatada e tamanho na qualidade fisiológica de sementes de feijão cv. Carioca Precoce. Informativo ABRATES, Londrina, v.13, n.3, p. 271, 2003. 